\title{
GRUPO DE GESTANTES: ESPAÇO DE CONHECIMENTOS, DE TROCAS E DE VÍNCULOS ENTRE OS PARTICIPANTES ${ }^{1}$
}

\author{
PREGNANT WOMEN GROUPS: KNOWLEGES, CHANGES AND LINKS OF SPAPE AMONG THE \\ PARTICIPANTS
GRUPOS DE MUJERES EMBARAZADAS: ESPACIO DE CONECIMIENTOS, CAMBIOS E VÍNCULOS ENTRE SUS PARTICIPANTES

\section{Graziele Strada Sartori ${ }^{2}$ Isabel Cristina Pacheco Van der Sand ${ }^{3}$}

\begin{abstract}
RESUMO: Na gestação passa-se por uma série de mudanças e a conseqüente adaptação pode gerar ansiedade e medo para quem a vive. Uma das formas de enfrentamento dessa situação pode ser a busca de grupos de gestantes. Este estudo busca: conhecer a percepção dos participantes de um grupo de gestantes sobre a vivência nessa atividade; conhecer a repercussão em suas vidas após o término dos encontros. A pesquisa é qualitativa, descritiva, exploratória, do tipo estudo de caso. Para a coleta de dados utilizou-se entrevista aberta e para análise foi utilizada a análise de conteúdo de Bardin. Dos quatro temas emergentes apresenta-se neste artigo: o grupo como um espaço de conhecimentos, de trocas e de vínculo; e, o grupo e as repercussões na vida dos participantes. Os grupos de gestantes podem ser terapêuticos para seus participantes, sendo pertinente a sua implementação como forma de assistir de modo integral às pessoas.
\end{abstract}

PALAVRAS-CHAVE - Grupo; Gestação; Operativo e Terapêutico.

ABSTRACT: During pregnancy there are several changes and consequent adaptations that might produce anxiety and fear. A form of confronting might be the participation in pregnant women groups. This study wants to know the perception of the participants in pregnant women groups and its repercussion in the women's lives after the meetings. It is a study with qualitative, descriptive and exploratory approach, of the case study kind. The data were gathered through non-structured interviews. For the analysis the proposition of Bardin was taken into consideration. Two out of four emergent themes two are presented in this article: the group as a space of knowledge, changes and links; and, the group and the repercussions in the participants' lives. The pregnant women groups can be therapeutic for their participants and they pertinent while integral form to assistance people.

KEY-WORDS: Operative Group; Pregnancy and Therapeutic.

RESUMEN: En el embarazo hay varios cambios y la adaptación consecuente pueden producir ansiedad y miedo. Una forma para confrontar puede ser la participación en los grupos de las mujeres embarazadas. Este estudio quiere conocer la percepción de los participantes en unos grupos de las mujeres embarazadas y a conocer la repercusión en sus vidas después de las reuniones. Es un estudio con el acercamiento cualitativo, descriptivo y exploratorio, un estudio del caso. Los datos se recogieron a través de las entrevistas non-estructuradas. Para el análisis, la proposición de Bardin se tuvo en la cuenta. De estos cuatro temas emergentes se presentan en este artículo: el grupo mientras un conocimiento, cambios y el espacio de eslabón; y, el grupo y las repercusiones en la vida de los participantes. Los grupos de las mujeres embarazadas pueden ser terapéuticos para sus participantes, y ellos son pertinentes mientras la forma íntegra a la ayuda a las personas.

\footnotetext{
${ }^{1}$ Este artigo origina-se de pesquisa intitulada "Nasce um pai, uma mãe, uma avó... o grupo de gestantes como um espaço de re-significar vivências", fruto do Trabalho de Conclusão de Curso, requisito parcial para obtenção do título de bacharel em Enfermagem, pela Universidade Regional do Noroeste do Estado do Rio Grande do Sul.

${ }_{2}$ Enfermeira graduada pela Universidade Regional do Noroeste do Estado do Rio Grande do Sul - UNIJUÍ, auditora e responsável pela organização de grupos operativos em saúde na UNIMED de Santa Rosa/RS.

${ }^{3}$ Enfermeira. Mestre em Enfermagem. Professora Adjunta do Departamento de Ciências da Saúde, da UNIJUÍ, Ijuí, RS. e-mail: isabel@unijui.tche.br
} 
PALABRAS CLAVES: Grupo; Embarazo; Operativo y Terapéutico.

\section{INTRODUÇÃO}

Percebemos, na atualidade, a necessidade da grupalidade em quase todos os tipos de ambientes em que convivemos. Significa segundo MUNARI \& ZAGO (1997) que, através do grupo o homem pode desenvolver atividades em suas relações pessoais, realizar tarefas, oferecer e receber ajuda.

Ao referir-nos ao termo grupo, consideramos o conceito de PICHONRIVIĖRE (2000, p. 234) que diz que:"grupo é o conjunto restrito de pessoas, ligadas entre si por constantes de tempo e espaço, e articuladas por sua mútua representação interna, que se propõe, de forma explícita ou implícita, a uma tarefa que constitui sua finalidade".

A experiência que temos nesse campo e o conhecimento que adquirimos sobre este tema nos fazem considerar que a atividade pode ser significativa para seus participantes, constituindo-se em importante recurso para assistir as pessoas. Este "assistir" tem relação direta com a área da saúde, em especial com a enfermagem, uma vez que o cuidado às pessoas é o principal instrumento desta. O trabalho de natureza grupal, para o enfermeiro, se desenha como mais uma possibilidade da inter-relação com sujeitos de diferentes profissões.

$\mathrm{Na}$ Universidade Regional do Noroeste do estado do Rio Grande do Sul (UNIJUÍ), instituição na qual este estudo foi realizado, é disponibilizado um componente curricular no Curso de Enfermagem, que aborda temas relacionados ao trabalho grupal e que estimula seus alunos a uma atenção especial ao mesmo, buscando conscientizar que conhecer e trabalhar com grupos é essencial para desenvolver ações que promovam saúde.

Percebemos que o ser humano busca conviver em certos grupos, mais específicos, em determinadas fases de sua vida, especialmente em momentos de crise, quando sente necessidade de ser acolhido e identificado com pessoas que vivenciam as mesmas situações que as suas. A fase da gestação é uma dessas situações, quando a mulher e companheiro/família passam por uma série de mudanças em suas vidas, pois, conforme Viçosa (1997, p.305), neste período, além das mudanças corporais da mulher, vão acontecer mobilizações emocionais em sua vida, para adaptar-se ao novo papel que lhe é "dado" a partir desta vivência. Essa adaptação pode gerar ansiedade e medo para quem a vive. Vale considerar que, ao longo dos anos, a gravidez deixou de ser assunto exclusivo da mulher, pois conforme JENERAL (2000), ela transforma a identidade tanto de homens como de mulheres, e é influenciada por aspectos afetivos, sociais, psíquicos e culturais que abrangem o casal e a família, exigindo adaptações destes a um novo contexto de vida, no âmbito pessoal, familiar e sociocultural.

Tendo como base as perspectivas descritas até aqui a respeito da gravidez, estudos apontam que a participação em grupos, por parte das pessoas envolvidas com o processo de gestar, tem se mostrado de grande valia. Em especial, se referindo a grupos de gestantes, estes vêm trazer aspectos terapêuticos e oferecer suporte a estas pessoas, uma vez que, segundo MUNARI \& RODRIGUES (1997, p.14, a) "um grupo pode ajudar pessoas durante períodos de ajustamentos a mudanças, no tratamento de crises ou ainda na manutenção ou adaptação a novas situações".

VIÇOSA (1997) contribui referindo que nos grupos de gestantes se cria um espaço onde os participantes podem dizer seus problemas e refletir sobre eles. Nesta perspectiva há o incentivo para a troca de experiências comuns entre os integrantes e os coordenadores do grupo, o que gera mobilizações entre os participantes. PICHONRIVIÈRE (2000, p. 143) aponta que, "pela mobilização das estruturas estereotipadas por causa do montante de ansiedade que 
desperta a possibilidade de mudança ${ }^{4}$, chegamos a captar no aqui-agora-comigo e na tarefa do grupo, um conjunto de experiências, afetos e conhecimentos com os quais os participantes do grupo pensam e atuam,tanto em nível individual como grupal".

Frente ao exposto este estudo busca saber: qual a percepção dos participantes de grupos de gestantes sobre esta vivência e qual a repercussão desta em suas vidas após o término dos encontros?

Considerando 0 objeto de estudo delineou-se para a investigação os seguintes objetivos: conhecer a percepção de gestantes e acompanhantes em relação à vivência em grupo de apoio psicoprofilático à gestação; identificar a repercussão desta vivência na vida dos participantes após o término dos encontros.

\section{CAMINHO METODOLÓGICO}

Considerando os objetivos deste estudo optamos pela pesquisa de natureza qualitativa., entendida conforme apontamentos de MINAYO (1994, b). A mesma caracteriza-se, ainda, como descritiva e exploratória em consonância com GIL (1999), e é do tipo estudo de caso, considerando as idéias de BODGAN; BIKLEN (1994). Nesta pesquisa, o caso em estudo é o Curso de Preparação para o Parto e Noções de Puericultura, implementado pela Universidade Regional do Noroeste do Estado do Rio Grande do Sul - UNIJUÍ., a partir do ano de 1992 por professores do Curso de Graduação em Enfermagem (VAN DER SAND, 1994), e que será referido aqui como "Grupo de Gestantes".

O grupo de gestantes, em estudo, é do tipo homogêneo, em virtude do fato de seus participantes compartilharem de uma mesma vivência: a gestação. Esta atividade grupal é caracterizada como operativa, terapêutica, pois centra-se na socialização da vivência da gestação, característica baseada em apontamentos de PICHON-RIVIÈRE (2000) e de CAVALCANTE (1999). Além da gestante,

\footnotetext{
4 Manifestada neste período pela possibilidade de alteração de papéis, descrita anteriormente, conseqüente da chegada de um novo membro à família.
}

permite a participação de um acompanhante, os quais podem falar sobre a vivência da gestação, trocar informações e aprender sobre ela. Tem a coordenação de profissionais de saúde. O número de participantes varia de cinco a doze, incluindo os acompanhantes. Os encontros são semanais, em média oito, a depender da necessidade de cada grupo, sendo que a metodologia implementada baseia-se na abordagem de assuntos pré-definidos pela coordenação e discutidos com os elementos do grupo, referentes à gravidez, parto e puerpério. Em geral, estes assuntos são acompanhados de técnicas de animação grupal, com a finalidade de "aquecer" a interrelação dos participantes. Vale ressaltar que, apesar da pré-definição de temas, o enfoque está voltado para assuntos que emergem do próprio grupo.

Os sujeitos deste estudo, escolhidos aleatoriamente, são gestantes e/ou acompanhantes que participaram de uma das edições do Grupo de Gestantes da UNIJUí, em número de sete (determinado pela saturação dos dados), sendo seis mulheres (uma avó e cinco ex-gestantes) e um homem (pai). Para participar do estudo os sujeitos deveriam ter freqüentado pelo menos uma das edições do Grupo de Gestantes, em que a pesquisadora, que faria a coleta dos dados, não se fazia presente, além de estar cientes dos requisitos e normas adotadas na pesquisa, bem como, desejar participar dela.

A coleta de dados se deu pela entrevista, gravada em audiotape, com pergunta aberta, em consonância com apontamentos de MINAYO (1994), tendo como pergunta norteadora: "Conte-me como foi para você ter participado de um grupo de gestantes?" Se o sujeito não discorresse sobre as repercussões da atividade em sua vida, fez-se a seguinte questão: "Você julga que houve alguma repercussão desta vivência na sua vida? Se sim, fale-me sobre isso".

Para a análise dos dados utilizamos a técnica de análise de conteúdo de BARDIN (1977), que possibilita encontrar, conforme GOMES (2000), descobrir o que está por trás dos conteúdos manifestos. 
Foi utilizada a assinatura de um termo de consentimento livre e informado por parte dos sujeitos investigados, que continha dados acerca da relevância da pesquisa, seus objetivos e metodologia e garantia-lhes anonimato, isenção de qualquer dano, bem como uso dos dados somente para fins científicos. O termo, conforme preconiza a Resolução 196/96 do Conselho Nacional de Saúde do Ministério da Saúde, continha endereço para eventuais contatos dos sujeitos como as pesquisadoras.

Os dados do estudo, após análise, foram expostos aos sujeitos a fim de que fossem validados, o que se deu através da assinatura de um termo de validação. $\mathrm{Na}$ transcrição dos fragmentos de falas foram utilizados codinomes específicos e diferentes para cada sujeito.

\section{RESULTADOS E DISCUSSÃO}

Após a leitura exaustiva das entrevistas, procuramos apreender nas falas dos sujeitos as idéias relacionadas e agrupá-las em temáticas, de acordo com a similaridade das informações. Desta forma, emergiram quatro temáticas de análise, das quais discorremos sobre duas: o grupo: um espaço de conhecimentos, de trocas e de vínculos; o grupo e as repercussões na vida dos participantes.

TEMA 1: o grupo: um espaço de conhecimentos, de trocas e de vínculos entre os participantes

Embora o enfoque central do grupo de gestantes não seja a transmissão de informações, surgem diversas situações, durante as atividades realizadas no campo grupal, em que a quantidade de informações manifestas é substancialmente importante e indispensável de serem trabalhadas no momento vivido pelo grupo, uma vez que emergem deste. Neste sentido vale lembrar de MUNARI \& RODRIGUES (1997, p. 19) quando referem que "embora a informação cognitiva seja condição necessária para a mudança de comportamento, na maioria das instâncias, por si só não é suficiente para alterar a postura dos participantes, frente ao assunto. Poucas pessoas mudam apenas pela informação recebida". Porém, percebemos que a troca de conhecimentos possui também importante papel na dinâmica grupal, pois os participantes encontram no grupo local onde podem expressar suas dúvidas e buscar a melhor forma de solucioná-las ou não.

"É uma importância muito grande, porque te dá uma tranqüilidade e algumas coisas, é... Esclarece algumas coisas que você tem dúvida, e você pode indagar estas coisas". (Castor).

Conforme expressa Castor, o grupo dá a possibilidade de manifestação de dúvidas e dificuldades de cada um e de todos. Isso porque trabalha a partir de uma situação concreta expressa no "aqui e agora do grupo", o que facilita o entendimento e a adesão aos conhecimentos (re)velados por parte das pessoas envolvidas.

Ter idéia das situações futuras da gestação e mesmo daquilo que ocorrerá após a mesma traz bem-estar e tranqüilidade às pessoas grávidas. Este tipo de informação não sugestiona as pessoas, ao contrário, previne a instalação de ansiedades desnecessárias, provocadas pelo desconhecimento das situações próprias da gravidez, parto e puerpério (ÁVILA, 1998).

"Pra ver coisas novas, porque por ser
uma gravidez não... vamos dizer
assim... ocorrem alterações né, e pra
mim, as duas gestações foram muito
bem, então eu não tinha nada de
alterado, e... o mais importante é
compartilhar as coisas novas que a
gente aprende". (Hyades)

A necessidade de aprender e de "ver coisas novas" nos parece estar intimamente relacionada à idealização das "pessoas grávidas" de seu futuro enquanto pais e avós. As pessoas quando se projetam enquanto pai/mãe ideal buscam no grupo um lugar para aprender a lidar com estes novos papéis. 
"Foi interessante nesse sentido assim [...] até várias coisas que eram faladas a gente já sabia, mas eu tentei fazer, passar por aquele momento assim, fazendo de conta que eu não sabia de nada, e ser só grávida mesmo e estar participando da experiência de compartilhar com outras mulheres, com maridos né, que tinha lá, tinha avós também, com as colegas que estavam na coordenação, com os estagiários que estavam lá também participando". (Polaris)

A expressão de Polaris revela o aspecto da universalidade, expressa por Yalon apud MUNARI \& RODRIGUES (1997) como um dos fatores terapêuticos dos grupos. Conforme esta autora, a universalidade se coloca durante a interação grupal, quando os seus participantes conseguem se dar conta de que não são os únicos que têm dúvidas e ansiedades e essa percepção parece ser reconfortante, trazendo esperança de que as coisas podem ser diferentes.

É interessante apontar que Polaris, apesar de ser profissional de saúde, e já ter conhecimento de várias temas discutidos no grupo, expõe a necessidade de ser "só grávida" e ser vista "como as outras", expressando o quanto a "universalidade" realmente é terapêutica, em se tratando de um grupo de iguais e que vivenciam as mesmas alegrias e dificuldades.

A questão da interdisciplinaridade da equipe de coordenação do grupo pode ser percebida também como fator significativo para os participantes, uma vez que, conforme expressa a fala dos entrevistados, a abordagem de outros aspectos que não só àqueles relativos à gravidez orgânica é considerada como fator positivo.

"A gente aprendeu fazer alongamentos, tipos de alongamentos, as formas, depois com o passar do tempo e das semanas, que ia se chegando perto da, do bebê nascer, como dormir com mais tranqüilidade né, então até foi interessante. A gente também fazia técnicas de grupo, onde a gente pôde montar, desde o cardápio da gestante, estas coisas, da alimentação o que pode, o que se pode cuidar, essas coisas". (Canopus)

Salientamos que o grupo em estudo tem se configurado, ao longo dos anos, de forma interdisciplinar, sendo que, na época da participação dos sujeitos entrevistados, a coordenação dos encontros se dava por professores e acadêmicos dos cursos de Enfermagem e de Nutrição e contava-se com um profissional da Educação Física. Atualmente a atividade conta também com a Fisioterapia e a Psicologia, sem a figura do professor de Educação Física. Conforme explicitado por CAMPOS et al (2003), mulher/companheiro que se encontram esclarecidos e informados e que tiveram a oportunidade de falar sobre seus anseios e planos em prol de dar termo à gravidez, tornam-se menos ansiosos e o medo frente ao desconhecido tende a diminuir. Assim, abordando a gravidez de forma holística, através de grupos coordenados por equipes interdisciplinares, é favorecido um melhor entendimento do momento vivido, já que se trata dos temas trazidos pelos participantes.

ÁVILA (2000) pondera que as informações oferecidas pelo profissional devem ser acompanhadas de reflexão, acerca dos sentimentos suscitados em cada pessoa ou casal diante destas informações. Tais idéias corroboram os princípios que pautam as ações do grupo estudado, visto que cada profissional da equipe de coordenação utiliza-se de seu núcleo de conhecimento no sentido de acolher as manifestações ali expressas, desenvolvendo sua função de Ego-auxiliar. Para ZIMERMAN \& OSÓRIO (1997) este é um dos atributos necessários a um coordenador de grupo, quando empresta, por algum tempo, suas funções de Ego, às pessoas que ainda não as possuem. Assim, auxilia o grupo a "pensar" seus sentimentos:

"Foi abordado todo o aspecto, eu acho que não chegou a faltar nada, sabe". (Quasar) 
A percepção do grupo como "completo", como expressa Quasar, tem relação com a questão do aprendizado, mas também com o "acolher" daquele momento, vivido pelos participantes, de forma integral e satisfatória, o que vai além da aquisição de conhecimentos. MUNARI \& RODRIGUES (1997) apontam a importância daquilo que se aprende com o próprio movimento do grupo, pois é através destas vivências que as pessoas podem aprender como são vistas pelas outras pessoas, como elas se colocam frente a si próprias, frente aos outros e, ainda, porque agem de determinada forma em seus relacionamentos.

O fato de perceber a si próprios e aos outros faz com que as pessoas, que passam por um momento de crise, possam ter a oportunidade de reajustar-se às novas realidades, uma vez que os grupos de gestantes oferecem essa possibilidade. Cabe destacar que a gestação é um período de crise, por constituir-se num momento de transição do que está em vigor, para o que irá vigorar, re-significando vivências.

O contexto grupal é caracterizado por trocas entre seus participantes e este revelase um dos principais potenciais terapêuticos do grupo em questão, pois é através das trocas que ocorre a maioria das configurações já descritas e importantes neste campo grupal.

"Então a pergunta, daí a gente falava, daí às vezes quem orientava ainda falava alguma coisa, tinha uma parte, e depois tinha uma socialização, mas todo mundo participava, porque na verdade um perguntava alguma coisa duma prática daquelas, ou, viu alguém passar por aquilo e, sempre colocavam uma experiência. Isso é uma coisa muito (se referindo as trocas citadas anteriormente) positiva né, porque isso vem enriquecer o grupo, porque a gente consegue absorver que aquilo que elas estavam colocando, de fato era o que estava acontecendo, eu acho um trabalho bem bonito". (Canopus)
A comunicação entre os membros do grupo é uma das oportunidades ímpares que o campo grupal propicia. A comunicação expressa neste tema não se constitui apenas na expressão verbal dos componentes do grupo e sim, também, na não verbal, pois esta segunda, muitas vezes, é tanto ou até mais importante do que o expresso verbalmente, demandando sensibilidade para interpretá-las. Nos grupos homogêneos, como no caso do grupo de gestantes, onde todos os participantes compartilham da mesma situação - a de gestar -, um elemento considerado terapêutico que deve ser valorizado é o fato de compartilharem uma linguagem comum, o que faz com que, mutuamente, se sintam acolhidos, respeitados e, sobretudo, compreendidos (ZIMERMAN \& OSÓRIO, 1997, p. 122). PICHON-RIVIÈRE (2000, p. 174) corrobora afirmando que "de acordo com a teoria da informação, o que permite ao receptor que compreenda a mensagem transmitida pelo transmissor, através de operações de codificação e decodificação, é uma semelhança de esquemas referenciais".

Constata-se que a expressão de um dos componentes do grupo faz com que os outros identifiquem, neles mesmos, a vivência da mesma situação. Desta forma além da universalidade, o grupo em estudo configurase no que ZIMERMAN (2000) aponta um espaço de ressonâncias, o que consiste no fato de que, como um jogo de diapasões acústicos ou de bilhar, a comunicação trazida por um membro do grupo ressoa em outra, a qual, por sua vez, transmite um significado afetivo equivalente, ainda que embutido numa narrativa de embalagem bem diferente (ZIMERMAN, 2000).

"É um momento mais do que a coisa assim do que aprender coisas, né? Tem a coisa de tu vê o que os outros te dizem de como é que foi a passagem por esta experiência [...] O fato de contar coisas pra alguém, como que tu faz, talvez ajude a que elas também se tranqüilizem ou repensem o jeito que estão fazendo, considerem aquilo, 
decidam por aquilo que estão fazendo também". (Polaris)

A partir das trocas de experiências, as pessoas participantes do grupo apreendem o que consideram importante para si, têm a oportunidade de elaborar e re-significar a sua própria vivência enquanto pai e mãe, e executá-las, se assim o julgarem pertinente. Este processo tem vinculação com o que PICHON-RIVIĖRE (2000) chama de esquema conceitual referencial operativo (ECRO), fator essencial para que haja aprendizagem da realidade. Através dele, cada integrante do grupo traz um esquema referencial próprio (experiências, sentimentos...) que interage com o dos outros participantes do grupo, através de um movimento espiral, configurando-se o ECRO. Este se constitui extremamente importante na medida em que se estrutura como um processo contínuo e com oscilações, aberto a conhecimentos e questionamentos.

É claro, na expressão de Polaris, que no grupo realmente se configura a possibilidade de formação do ECRO. Porém, é preciso levar em consideração que a mudança de um esquema referencial exige a interação subjetiva dos componentes do grupo e que esta ocorre gradativamente ao longo dos encontros. Porém, não significa que todos passem a pensar de uma mesma maneira após o processo de formação de um novo esquema referencial. CAVALCANTE (1999, p. 35) afirma que "unidade não significa, no sentido dialético, exclusão de opostos, de conflitos, mas inversamente a unidade inclui e implica a existência de opostos em seu seio". O que se propõe, na verdade, é o questionamento dos comportamentos, crenças e afetos de cada um, a fim de romper estereótipos. O potencial terapêutico se dá no momento em que cada "pessoa grávida" tem a possibilidade permanente de rever seu próprio referencial, a partir da experiência de cada componente do grupo. Isso pode se configurar dentro ou fora dele.

A ansiedade também emerge no conteúdo das falas com intensidade, sendo importante atentar para o fato de que tal manifestação é intensificada no período gravídico, tanto pela gestante, como pelos seus familiares. Na maioria das vezes, a ansiedade se relaciona com o desconhecimento do "novo", das situações que estão vivenciando e daquelas que ainda irão vivenciar enquanto mãe, pai, avó entre outros. Sírius contribui para esta percepção.

"É, e aí parece que tu tem que ir lá pra aprender alguma coisa, e na realidade não, o que tu vai, o que vai acontecer lá, é trocar experiências e, assim uma coisa que eu me lembro, era a ansiedade que todo mundo tinha. Acho que lá, eu não tenho bem certeza, mas eu acho que no nosso grupo, a maioria era... primeiro filho, sabe. Então, todo mundo, um mais ansioso que o outro né, mas foi muito... muito legal". (Sírius).

Segundo NINA (1997, p.90), a ansiedade "é um estado mental ligado às emoções e coexistência de sentimentos, conscientemente perceptíveis relacionados à causa específica: o perigo". As ansiedades, segundo PICHON -RIVIĖRE (2000), são de dois tipos: "depressiva", expressa com o medo da perda de uma determinada condição e, a "paranóide" frente ao medo do ataque da situação a ser instaurada. Consideramos que a presença de ansiedades é importante e necessária para uma boa condição de elaboração da nova condição de pai e de mãe. PICHON-RIVIÈRE (2000), ao mencionar a presença de ansiedade, refere que ela se configura como um mecanismo de segurança patológica. É justamente a respeito dessas ansiedades que trabalha 0 grupo de gestantes, oferecendo a oportunidade para as pessoas elaborarem a melhor forma de minimizá-las, através do compartilhamento das mesmas. Ocorre que "mexendo" nos estereótipos de cada um, o grupo pode enfrentar, então, as situações de mudança.

Depreende-se do depoimento de SíRIUS que todas eram primigestas e vivenciavam ansiedades em comum, o que revela a função de "espelho" que cada pessoa grávida representa ao grupo. Esta função para ZIMERMAN E OSÓRIO (1997, 
p.121) é conseqüência do jogo contínuo de identificações projetivas e introjetivas colocadas no campo grupal. Para estes autores "trata-se de uma expressão muito feliz, pois ela traduz a ação terapêutica do grupo, que se processa através da possibilidade de cada um mirar e se refletir nos outros e, especialmente, de poder reconhecer no espelho dos outros, aspectos seus, que estão negados em si próprios". A atividade grupal coloca-se como possibilidade, a cada componente, de discriminar, afirmar e consolidar a sua própria identidade.

Ainda em relação às ansiedades expressas no grupo, gostaríamos de acrescentar, como função deste também, a de ser um continente das manifestações de cada um dos participantes. ZIMERMAN (2000), ao se referir à função de continente do grupo, compara esta aos cuidados de uma mãe em relação ao seu filho, a qual acolhe as necessidades, decodifica o significado delas e lhe dá um sentido e, em seguida, devolve transformada e apropriada às condições da criança. Assim, o grupo possui a tarefa de acolher as angústias e necessidades dos participantes, reconhecer e aceitá-las e devolver a cada um a possibilidade de mudança.

Muito do que foi descrito e analisado até agora está expresso na fala de Canopus, revelando que a atividade em estudo trata-se de um grupo, e não de um curso. Vale considerar que hoje esta atividade recebe 0 nome de "Grupo de Gestantes e Familiares", pois seus coordenadores julgam ser a que melhor se adapta as características da mesma.

"O curso, pra mim, é uma coisa que tu vai independente de tu atingir a tua expectativa ou não. Agora, o grupo não! Grupo é aquele, assim, que tu tá louca pra se encontrar, tu vai se reunir, tu vai colocar as tuas expectativas, né, os pontos negativos. Até porque a gente socializa muito [...] Então, eu vejo como grupo quando você consegue abrir as coisas pro grupo. Já se fosse curso, não.(...). No grupo você tem necessidade de ir, socializar, por mais que daqui a pouco tu vai fugir daquilo, da regra do dia né (do tema agendado para o encontro), o que tava prédeterminado. Daqui a pouco, muitas vezes, a gente fugia, nós fizemos ... no final nós fizemos dois encontros a mais, porque acabamos pegando ganchos daquilo que era colocado, e daí a gente não terminava mais, cada uma queria colocar, cada uma queria falar, dizer sua experiência, no caso a M. já tinha filhos, então colocava experiências também dos manos, com os futuros bebês, é uma experiência bem bacana". (Canopus).

É clara a "pertencência" de Canopus ao grupo ao qual integrou-se durante a gestação. CAVALCANTE (1999, p. 30) indica que "a pertença (ou pertencência) consiste no sentimento de fazer parte de um grupo, podendo, neste momento, ocorrer uma identificação mais intensa com os processos grupais". Isso é importante e necessário para a configuração de muitos aspectos terapêuticos do grupo em questão. A interação entre os participantes do grupo, expressa positivamente por Canopus, tem relação com a vinculação (vínculo) que se configura entre os participantes. A colaboradora sente o grupo como dela, no qual deposita expectativas e consegue sentirse à vontade, reforçando a questão da pertencência e da função continente do grupo em estudo.

O termo vínculo, utilizado neste estudo, está relacionado à forma de ligação entre partes que estão unidas e inseparáveis, mesmo visivelmente delimitada entre si (ZIMERMAN, 2000). Este mesmo autor introduz o vínculo do "reconhecimento" nas inter-relações pessoais ${ }^{5}$, aspecto importante nas relações vinculares apresentadas no grupo em questão. Para o autor, em uma atividade grupal pode haver: o "reconhecimento", relacionado ao fato de que todo conhecimento novo é um reconhecimento de prévias repressões,

\footnotetext{
${ }^{5}$ Além dos vínculos L e H, e o vínculo K, respectivamente descritos por Freud e Bion (ZIMERMAN, 2000).
} 
reminiscências e pré-concepções; o "reconhecimento do outro" necessário para o crescimento mental do indivíduo, que reconhece que o outro não é um mero espelho seu, que é autônomo e tem valores diferentes dos seus; "ser reconhecido aos outros", que se refere ao desenvolvimento de sua capacidade de consideração e de gratidão em relação à presença dos outros; e o quarto e último é o de "ser reconhecido pelos outros", que se relaciona ao fato de as pessoas necessitarem ser reconhecidas para a manutenção da auto-estima. Ser reconhecido e valorizado pelos demais e saber que ele realmente existe como uma individualidade é uma necessidade humana (ZIMERMAN, 2000).

As expressões que seguem parecem evidenciar o vínculo do "reconhecimento" aludido anteriormente, em seus diferentes aspectos:

"Então cada dia que tinha curso a gente esperava o dia chegar, pra fazer, pra poder se encontrar com o pessoal, com os colegas". (Hyades)

"Acho que acabei deixando as outras preocupadas, porque elas estavam lá no grupo e, as duas semanas que eu não fui, elas estavam preocupadas comigo, tanto é que elas me ligavam: ah! Como é que tu tá, ai que pena, né, não deu pra ti vir, a gente sentiu assim que... como é que eu vou te dizer, a gente tinha muitas afinidades no grupo né, porque a gente contava a vivência nossa do dia-a-dia uma pra outra, e isso circulava, né?" (Canopus)

As relações vinculares estabelecidas no grupo têm ligação também com a coesão grupal, expressa por Yalon apud MUNARI \& RODRIGUES $(1997$, a) como fator curativo dos grupos operativos. A coesão do grupo congrega os vínculos entre todos os participantes e a manutenção desta condição garante muitas características do grupo, como suas facilidades, dificuldades, valores, compromisso e confiança mútua. A coesão grupal é percebida nas colocações de Canopus e Hyades, que expressam claramente suas vinculações com o grupo e o quanto isso thes era importante. PICHONRIVIĖRE (2000), ao se referir a essa sensação de pertencer a um grupo, refere que o sujeito participante tem a possibilidade de adquirir uma identidade, uma referência básica, que lhe permite localizar-se situacionalmente e elaborar estratégias para mudanças, o que reforça a importância de atividades de natureza grupal operativa junto a gestantes e seus familiares, os quais passam por uma situação vivencial transitiva em suas vidas, e que portanto indica possibilidade de mudanças.

\section{TEMA II - $O$ GRUPO E AS REPERCUSSÕES NA VIDA DOS PARTICIPANTES}

Após o término de cada edição do grupo em estudo os participantes deixam de se encontrar e retornam para o cotidiano, sem a convivência com os "colegas" de grupo. Porém, foi possível compreender que a convivência no grupo trouxe repercussões para a vida dos participantes, mesmo após desligarem-se dele.

Algumas destas repercussões são percebidas pelos participantes logo após o final da edição do grupo, como é o caso daquelas relacionadas ao momento do parto.

"Acho que muita da nossa experiência
do parto, de ter sido tranqüilo, um pouco
pelo meu jeito, um pouco pelo curso,
também acho que foi muito legal, foi
tranqüilo sabe, rápido, depois é
diferente, mas antes a preparação
assim foi legal acho que foi muito
interessante, acho que eu aproveitei
muitas coisas do curso nesse momento,
especialmente no momento do parto né
também". (Polaris)

No grupo há também ocorre uma visita às maternidades do município, a fim de que os participantes tenham noção mais aproximada do que poderão passar durante o parto, podendo optar pela unidade hospitalar que considerarem adequada. ÁVILA (1998) menciona que a esta visita funcionaria de 
modo a "facilitar um 'ensaio' psicológico das pessoas grávidas para poderem lidar com 0 momento do parto, atenuando a ansiedade, conhecendo as vantagens de cada tipo de parto e trabalhando as vivências despertadas por cada tema".

O desenvolvimento de tranqüilidade, após conhecimento do "novo", parece ter repercussões também no pai/companheiro, conforme expresso nas falas. Em este estando tranqüilo, conseqüentemente transmite segurança à mulher durante 0 processo de nascimento, tornando esta experiência menos traumatizante, de modo a deixar marcas internas mais positivas nos sujeitos que protagonizam este momento mãe, pai, filho.

"Em uma vez tu participando, tu tira tua curiosidade, você tira suas dúvidas e, você fica tranqüilo, como eu dizia, você fica tranqüilo, para que no momento do parto você dê tranqüilidade para sua esposa e, dê tranqüilidade pro médico, e, eu vi essa importância, né?" (Castor)

Na medida em que adquirem uma visão ampliada do momento do parto, o que se dá através das trocas de experiências ocorridas no grupo a este respeito e, também, pela visita às maternidades, os companheiros parecem mostrar-se empáticos e colaborativos na vivência do nascimento, se relacionando também melhor com a equipe de saúde que os assiste. Este aspecto contribui para a efetivação de um clima de harmonia, importante para este momento existencial transitivo, tão significativo na vida das pessoas.

"E se pôr no outro lado (refere-se a ser empático com os profissionais de saúde), pra ver como é que seria né? Se pôr no lado do médico, se pôr no lado da enfermeira, porque, muitas vezes, a gente quer o resultado final, que é o nascimento bem, coisa e tal, mas a gente não percebe que tem todo um contexto que trabalha pra que isso aconteça bem né. Se o médico tiver mal humorado já começa mal aí né? Se a enfermeira não estiver bem né, [...] também isso é importante, tem todo um contexto que envolve o parto, não é vai lá e nasceu né e, em a gente estando tranqüilo, passa essa tranqüilidade também, eu vejo assim" (Castor).

Estudo realizado por Brown aíd CURY (1995), com 64 primíparas, que buscou avaliar a relação psicológica da mulher e o uso de drogas no trabalho de parto, evidenciou que as características psicológicas da gestante têm relação direta com a quantidade de analgésico necessário para aliviar a dor no momento do parto. Pensamos que, de acordo com esse resultado, reforça-se a necessidade e a importância da atenção à mulher/companheiro, durante o período que antecede ao parto, de forma realmente integral, abrangendo também os aspectos emocionais e psicológicos da mulher/companheiro grávidos.

Percebemos que os grupos de gestantes oferecem essa possibilidade a seus participantes. Porém, é importante considerar que, de maneira nenhuma, é intenção do grupo de gestantes atingir a perfeição dos futuros pais. Ao contrário, tenta-se fazer deste espaço um local onde possam ser reveladas as limitações, as dificuldades e os temores de cada um e do grupo como todo. Desta forma, tenta-se, no campo grupal, elaborar estas manifestações, de modo que homens e mulheres possam vivenciar, também, o momento do nascimento e a maternidade/paternidade, propriamente ditos, do modo mais positivo possível. VIÇOSA (1997, p. 308) contribui aludindo que uma "boa preparação" deve "utilizar-se de um momento psicológico de intensa sensibilidade, para explorar, conhecer e orientar as gestantes, com o objetivo de ampliar ou criar um espaço psicológico necessário à interação com o(a) filho(a)".

Além das repercussões suscitadas no momento do parto, é possível apreender que a convivência grupal tem conseqüência também para a vida dos seus participantes, principalmente no que se refere à 
compreensão da importância que um momento de trocas possui para as pessoas.

"Eu percebo que foi importante para mim, que eu acho que mudou mesmo o fato de eu valorizar esta coisa... assim sabe, de eu valorizar esta coisa do compartilhar, esta coisa das experiências, da conversa, da reflexão, de trocar coisas, né, mesmo (...) Acho que mudou porque eu consegui ser mais assim, ah... Apesar de, nos primeiros tempos, stress... mas depois tu consegue ter a mente mais aberta um pouquinho, e, acho que entender também... Sabe, que não só um tem razão ou o outro, mas também de estar, assim... como a gente falava muito né, tem uma família inteira envolvida no cuidado da criança, não é só a mãe, não é só o pai, mas também tem... não é só a criança o centro de todas as coisas, mas também é a mulher o centro das diversas coisas que acontecem durante a gravidez né, e isso é uma coisa que eu passei a fazer diferente também depois do curso, depois do grupo". (Polaris)

"Pelo fato de tu conhecer outras pessoas, outras experiências, porque assim, lá tu vai ver que, assim, que cada pessoa tem um objetivo e pensava alguma coisa ou pros filhos, pra sua vida né, de repente estava com a... como é que eu vou dizer, tinha uma esperança naquele filho né. Tem uns que pensavam assim: há! Vou fazer um filho pra construir um mundo melhor, sabe, assim, aquela coisa de... aí tu fica olhando a vida de cada um, as suas experiências". (Sírius)

Os sujeitos do estudo revelam que tiveram a oportunidade de mudar a qualidade de suas vivências, o que reforça a possibilidade oferecida pelo grupo de fazer (re)conhecimentos de cada um e dos outros, o que é importante para o crescimento enquanto pessoas e enquanto integrantes de uma família e de uma sociedade. MUNARI \& RODRIGUES (1997) indicam que as mudanças configuradas no campo grupal podem ser classificadas como mudanças em relação a si mesmo, em relação às pessoas à sua volta e com relação ao meio em que vivemos.

A convivência em grupo tanto foi significativa para os entrevistados, que estes colocam e dão ênfase à importância de que todas as pessoas pudessem participar deste tipo de atividade, demonstrando e reforçando o valor que esta representou para a sua vivência enquanto pessoa.

\section{"Eu indiquei o curso para várias pessoas, porque é um momento também de você, no grupo colocar os teus anseios, as tuas dúvidas (...) então, sempre tu vai indicar né, porque aquilo que é bom pra gente, a gente quer que as outras pessoas conheçam né, então claro que indicaria, né?" (Canopus) \\ "Foi bem completo, de verdade, assim, eu sinto pena das mães que não participam, que a gente sempre tem alguma coisa pra aprender e trocar, foi excelente". (Quasar)}

A oportunidade de participar do grupo de gestantes parece, na voz dos sujeitos do estudo, vir enriquecer e complementar a assistência pré-natal individual, não significando que se baste por si mesma, mas evidenciando seu valor como prática que vem a somar na atenção à mulher/companheiro "grávidos", ressaltando a importância da integralidade da assistência.

\section{CONSIDERAÇÕES FINAIS}

A gravidez é um período de constantes modificações físicas, psicológicas e sociais na vida da mulher grávida e dos que a cercam, em especial o companheiro/futuro pai. A condição de gestar um filho gera necessidade de adaptação às novas condições e papéis de mãe, pai, avó, etc. Por esta razão, as pessoas envolvidas buscam maneiras de viver estes momentos de modo a minimizar ansiedades, fantasias e temores manifestos em relação ao processo de nascimento. 
O grupo de gestantes é uma dessas maneiras, em que através de um jogo de iguais, há condições para a formação de um espaço de considerável poder terapêutico para seus participantes. Este potencial se legitima na medida em que possibilita às pessoas, ao interagir no campo grupal, elaborem seus sentimentos em relação ao momento vivido.

$\mathrm{Na}$ conivência grupal há a possibilidade de geração de conhecimentos, uma vez que nela são expressos saberes de cada um. A mobilização destas informações permite um melhor entendimento do momento vivido pelo grupo e facilita a adesão aos conhecimentos revelados. Esta condição ajuda a consolidar a capacidade de cada participante em acolher e cuidar paternalmente e maternalmente do filho que está por vir.

A formação de um espaço de trocas de experiências e vivências no campo grupal se configura em condição indispensável para a mobilização dos estereótipos de cada um, o que ajuda cada participante a enfrentar as situações de mudança, uma vez que tende a "re-significar" suas vivências através do reconhecimento dos outros e de si.

Pensamos, que a atividade grupal deveria ser mais explorada, em especial pelos profissionais de saúde, pois se conforma em espaço singular para mudanças, podendo ser utilizado como importante recurso para assistir as pessoas.

\section{REFERÊNCIAS BIBLIOGRÁFICAS}

ÁVILA, A. de. Socorro doutor: atrás da barriga tem gente. São Paulo: Atheneu, 1998. BARDIN, L. Análise de conteúdo. Lisboa: Edições 70, 1977.

BOGDAN, R.; BIKLEN, S. Investigação qualitativa em educação: uma introdução à teoria e aos métodos. Trad. Maria João Alvarez, Sara Bahia dos Santos, Telmo Baptista. Portugal: Porto Editora, 1994.

CAMPOS, I. F.; SARTORI, G. S.; VAN DER SAND, I. C. P. Grupos de gestantes e familiares: uma alternativa de atenção interdisciplinar. [projeto de extensão do Departamento de Ciências da Saúde, UNIJUÍ]. Ijuí: Universidade Regional do
Noroeste do Estado do Rio Grande do Sul, Vice Reitoria de Pós Graduação e Pesquisa, 2003.

CAVALCANTE, M. B. G. O grupo operativo como estratégia de assistência de enfermagem: a prática revelando caminhos para a mudança no cotidiano de pacientes com transtorno mental. São Paulo, 1999, 229p. Dissertação (Mestrado). Escola de Enfermagem da Universidade de São Paulo. CURY, A. F. Psicodinâmica da gravidez. In: TEDESCO, J. J. de A.; ZUGAIB, M.; QUAYLE, J. Obstetrícia psicossomática. São Paulo: Atheneu, 1997. p. 77-84.

GIL, A. C. Métodos e técnicas de pesquisa social. 4. ed. São Paulo: Atlas, 1995.

GOMES, R. A análise de dados em pesquisa qualitativa. In: MINAYO, M. C. (org.) Pesquisa social: teoria, método e criatividade. Petrópolis, Rio de Janeiro: Vozes, 2000. cap. 4. p. 67-80.

JENERAL, R. B. R. Vivendo um futuro incerto: a vivência da gravidez em uma comunidade. São Paulo, 2000, 189p. Dissertação (Mestrado), Escola de Enfermagem da Universidade de São Paulo.

MINAYO, M. C. S. O Desafio do Conhecimento: pesquisa qualitativa em saúde. 3. ed. São Paulo, Rio de Janeiro: Hucitec - Abrasco, 1994.

MUNARI, B. D.; RODRIGUES, A. R. F. Enfermagem e grupos. Goiânia: AB, 1997.(a) MUNARI, D.B.; ZAGO, M. M. f.; Grupos de apoio/suporte e grupos de auto-ajuda: aspectos conceituais e operacionais, semelhanças e diferenças. Revista de Enfermagem da UERJ. Rio de Janeiro. v.5, n.1, p.359-366, 1997.

NINA, M. D. Estresse e ansiedade na gestação. In ZUGAIB, M.; TEDESCO, J.J.; QUAYLE. J. Obstetrícia Psicossomática. São Paulo: Aheneu, 1997.

PICHON-RIVIÈRE, E. O Processo Grupal. 6. ed. São Paulo: Martins Fontes, 2000.

VAN DER SAND, I. C. P. Curso de Preparação para o Parto e Noções de Puericultura como Atividade Curricular na Formação de Enfermeiros. Município e Saúde. v. 1, n. 3, p. 46-50, 1994.

VIÇOSA, G. R. Grupos com gestantes. In ZIMERMAN, D. E.; OSÓRIO, L. C. Como 
Trabalhamos com Grupos. Porto Alegre: Artes Médicas, 1997.

ZIMERMAN, D. E.; OSÓRIO, L. C. Como trabalhamos com grupos. Porto Alegre: Artes Médicas, 1997.

ZIMERMAN, D. E. Fundamentos básicos das grupoterapias. 2. ed. Porto Alegre: Artes Médicas, 2000.

Texto recebido em 22/06/2004

Aprovado para publicação em 31/08/2004 